\title{
BIODIESEL PRODUCTION FROM WASTE COOKING OIL SELECTING A SOLID CATALYST DERIVED FROM ACTIVATED COCONUT COIR
}

\author{
PUSHPA JHA $^{1}$ \& ANKUSH SONTAKKE ${ }^{2}$ \\ ${ }^{1}$ Department of Chemical Engineering, SLIET, Longowal, India. \\ ${ }^{2}$ Department of Chemical Engineering, IIT Guwahati, India.
}

\begin{abstract}
In the quest for cost-effective production of biodiesel, selection of cheap feedstocks and catalysts play the significant role. Waste cooking oil is abundantly available from all types of restaurants throughout the world. Catalyst selected for this feedstock should be heterogeneous. Coconut coir, which is biomass and source of carbon, was selected for its study as a catalyst for biodiesel production. This paper is based on a comparison of a solid catalyst by two processes: (i) sulphonation of coconut coir char (pyrolysed at $500^{\circ} \mathrm{C}$ for 3 hours) and (ii) digestion of pyrolysed coconut coir with $10 \% \mathrm{NaOH}$ at $70^{\circ} \mathrm{C}$ for 4 hours followed by sulphonation. Comparison of both the solid catalysts thus prepared was done based on their physical properties, total acid density, SEM and FT-IR analysis. The higher percentage of fixed carbon content, higher acid density and BET surface area, better morphological surface and pronounced presence of sulphonic $\left(-\mathrm{SO}_{3} \mathrm{H}\right)$, carboxylic $(-\mathrm{COOH})$ and hydroxyl $(-\mathrm{OH})$ groups favours the selection of catalyst prepared by the second method for further study for biodiesel formation using waste cooking oil as the feedstock. Effects of various parameters on biodiesel production: alcohol to oil ratio (A:O), time of reaction, reaction temperature and catalyst loading were studied. At the optimised conditions, the biodiesel conversion was $90.12 \%$. Biodiesel produced by the method was characterised regarding fuel properties and were found close with the standard values.

Keywords: activated carbon, Biodiesel, biomass, characterisation, coconut coir, esterification, FFA conversion, fuel, renewable energy, solid catalyst.
\end{abstract}

\section{INTRODUCTION}

Much has been reported related to the production of energy and value-added products from wastes and biomass [1]. At present, world's energy needs are met mainly through petroleum, coal and natural gas, which are limited sources. Their use contributes a lot towards greenhouse gases leading to global warming [2]. Tremendous efforts have been made towards using biodiesel as a substitute to petroleum fuel with various technical advantages such as lower overall exhaust emissions, biodegradability, availability of cheap substances as feedstocks, negligible sulphur content, excellent flash point and higher combustion efficiencies [3-4].

Among cheap feedstocks, waste oils and fats from domestic wastes and restaurants can also be used as raw materials, which result in a reduction in the cost of biodiesel production [5-6].

Currently, biodiesel produced from waste cooking oil is widely reported through homogeneous and heterogeneous catalysis. Homogeneous catalysts used in literature to produce biodiesel from waste cooking oil are $\mathrm{NaOH}, \mathrm{KOH}, \mathrm{CH}_{3} \mathrm{ONa}$ and $\mathrm{CH}_{3} \mathrm{OK}$. These catalysts help to produce biodiesel at a much higher rate [7]. However, feedstocks required should be highly refined. So to use waste cooking oil as a feedstock cost to refine is quite high. The cost of biodiesel production also depends upon the cost of catalyst and its separation after the formation. Numerous literature reports about heterogeneous catalysts. They are environment-friendly and can be easily separated and reused or regenerated [8]. 
Carbon-based solid acid catalysts are well reported for biodiesel conversion. It can be activated to produce highly porous material with a hydrophobic surface. These properties of the adsorbents become more desirable along with sulfonic acid as a functional group. Because of such advantages, research using a source of carbon as a precursor for catalyst preparation has increased [9-16].

Selection of carbon-based catalyst from biomass along with the cheap source of feedstock like waste cooking oil forms the way towards sustainable production of biodiesel as a renewable source of energy.

In this paper waste cooking oil has been used as a feedstock and coconut coir as a catalyst, which is again an agricultural waste and abundantly available in India in coastal areas. Two methods have prepared catalyst from coconut coir: the first method involves direct sulphonation of pyrolysed coconut coir $\left(\right.$ at $500^{\circ} \mathrm{C}$ ) using $98 \% \mathrm{H}_{2} \mathrm{SO}_{4}$ at $150^{\circ} \mathrm{C}$ [17]. The char thus obtained has been named as SCC. The second method involves digestion of pyrolysed coconut coir with $10 \% \mathrm{NaOH}$ at $70^{\circ} \mathrm{C}$ for 4 hours before subjecting the resulting char for sulphonation as treated in the first method. The char thus obtained has been named as DSCC. Both the catalysts are studied by their physical properties, total acid density, SEM and FT-IR analysis. Based on the comparison, DSCC is selected for its application of biodiesel production from waste cooking oil.

With waste cooking oil as feedstock and DSCC as a catalyst, the effect of various parameters, on biodiesel production for alcohol: oil ratio, time of reaction, reaction temperature and catalyst loading were studied. Optimized conditions chosen for biodiesel production are A:O ratio of 18:1, time of reaction of 7 hours, a reaction temperature of $65^{\circ} \mathrm{C}$ and catalyst loading of $5 \%$. At this condition, biodiesel conversion (FFA conversion) is $90.12 \%$. Properties of biodiesel thus produced, were compared with that of standard properties available in the literature.

\section{MATERIALS AND METHODS}

\subsection{Characterization of waste cooking oil}

Waste cooking oil was collected from local restaurants. There is the possibility that the oil must have been used more than once. The oil obtained was filtered to remove inorganic residues. Various physical properties as shown in Table 1 were determined using standard methods [18].

Analysis of waste cooking oil samples before and after esterification was done using Gas Chromatography (Agilent GC 7890A model).

\subsection{Catalyst preparation}

The coconut coir was washed with distilled water to remove dust particles followed by oven drying for 24 hours. The dried samples were ground so that fine particles passed through the $250 \mu \mathrm{m}$ screen. The material was collected, weighed and stored in the dry atmosphere. A defined amount of ground coconut coir was carbonised in a muffle furnace at $500^{\circ} \mathrm{C}$ for 3 hours. One part of the resulting char was subjected to sulphonation with $98 \% \mathrm{H}_{2} \mathrm{SO}_{4}$ at $150^{\circ} \mathrm{C}$ for 24 hours, which was washed thoroughly, filtered, and dried for collection as sulphonated coconut coir char (SCC) as one catalyst material. Another portion of resulting char was subjected to digestion with $10 \% \mathrm{NaOH}$ at $70^{\circ} \mathrm{C}$ for 4 hours. The process of digestion was 
followed by thorough washing, filtration and drying of resulting residue. The char obtained was subjected to sulphonation as with the first catalyst. This char was washed thoroughly, filtered and collected as second catalyst (DSCC).

\subsection{Catalyst characterization}

\subsubsection{Catalyst properties}

Catalyst properties as shown in Table 3, were estimated concerning proximate analysis, ultimate analysis and other analysis by adopting standard procedures [19-22].

\subsubsection{Comparison of SEMs of SCC and DSCC}

SEM analysis on SCC and DSCC were done using JSM6100 (Jeol) model. Micrographs are shown in Fig. 1.

\subsubsection{FT-IR study of SCC and DSCC}

FT-IR studies were done on SCC and DSCC, as shown in Fig. 2 using Bruker tensor 27 for the wavelength of $4000-700 \mathrm{~cm}^{-1}$.

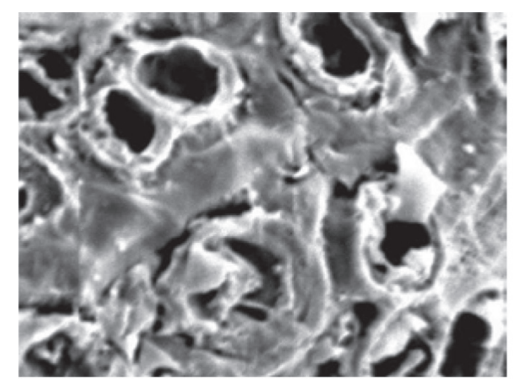

(a) SCC

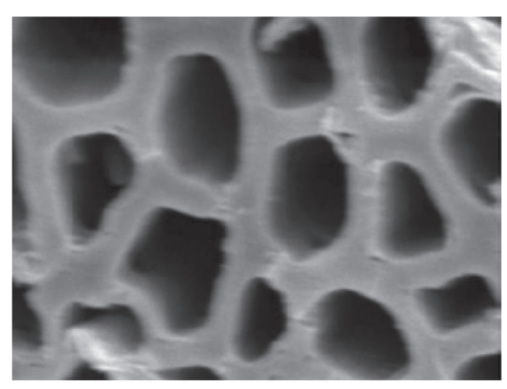

(b) DSCC

Figure 1: Comparison of SEM analysis of (a) SCC; (b) DSCC.

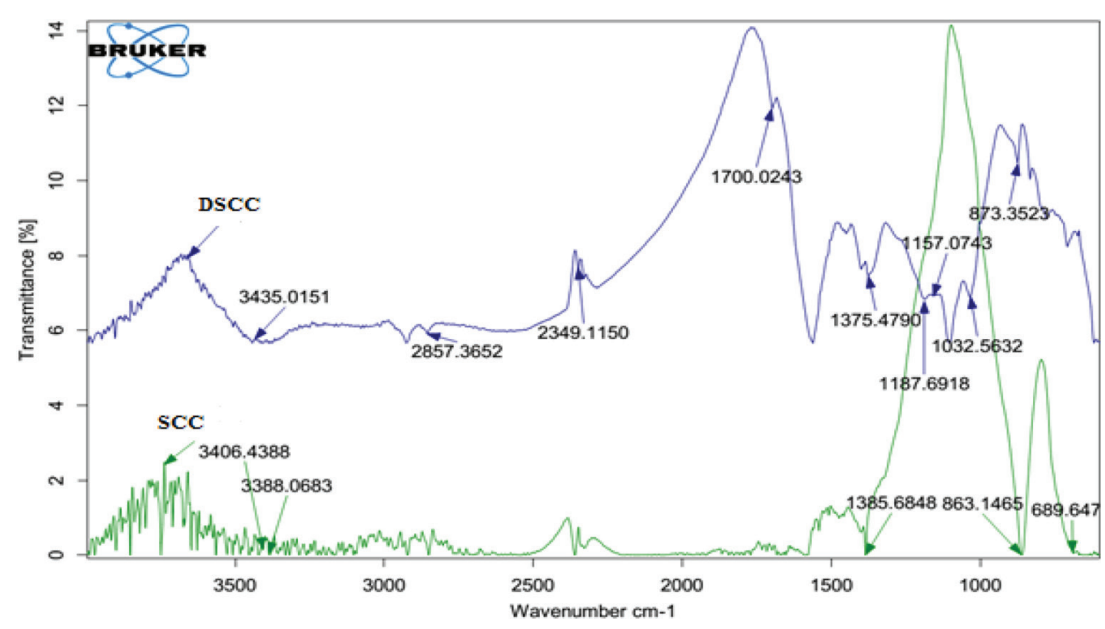

Figure 2: FTIR spectra of SCC and DSCC. 


\subsection{Biodiesel onversion (FFA conversion)}

Biodiesel is obtained from pre-dried waste cooking oil by esterification with methanol and pre-dried DSCC catalysts in $500 \mathrm{ml}$ three-necked flat bottom flask. Initially, this oil is heated to $110^{\circ} \mathrm{C}$ for $30 \mathrm{~min}$ to remove moisture thoroughly and then cooled down to various reaction temperatures. To find the optimum conditions for biodiesel production, effects of various parameters: alcohol to oil ratio (10:01, 13:01, 15:01, 18:01 and 20:01), catalysts loading $(2 \%$, $3 \%, 4 \%, 5 \%$ and $6 \%$ of oil $)$ and temperatures $\left(50^{\circ} \mathrm{C}, 55^{\circ} \mathrm{C}, 60^{\circ} \mathrm{C}\right.$ and $\left.65^{\circ} \mathrm{C}\right)$ were studied. The maximum reaction time was kept for 8 hours as there was no further change in FFA conversion beyond this time. The reaction products were FAME (biodiesel) along with non reacted alcohol. Collected FAME amount was measured using GC as mentioned in section 2.1 and stored for further characterisation. The FAME conversion expressed as a mass percentage [17], has been calculated using eqn (1)

$$
\text { FAME yield }=\frac{\sum \text { Area of peak except } C 17: 0}{\text { Area of peak } C 17: 0} \times 19.8
$$

In eqn (1), 19.8 is a dilution factor for internal standard methyl heptadecanoate solution (C17:0).

The analysis of gas chromatograph is shown in Fig. 6.

\subsection{Characterization of biodiesel produced}

Biodiesel produced at optimised conditions were subjected to determinations of its properties as a fuel. Calorific values, density, kinematic viscosity, cloud point, pour point, cetane number, flash point and an acid value of biodiesel produced were determined and compared with the standard methods available in the literature [23-24].

\section{RESULTS \& DISCUSSIONS}

\subsection{Characterization of waste cooking oil}

Waste cooking oil was characterised as mentioned in section 2.1 regarding various properties (Table 1). The acid value of the waste cooking oil was $2.0 \mathrm{mg} \mathrm{KOH} / \mathrm{g}$, which is the reasonable

Table 1: Physical properties of waste cooking oil samples.

\begin{tabular}{ll}
\hline Physical properties & Quantity \\
\hline Density $\left(\mathrm{g} / \mathrm{cm}^{3}\right)$ & 0.90 \\
Viscosity $@ 40^{\circ} \mathrm{C}\left(\mathrm{mm}^{2} / \mathrm{s}\right)$ & 32.0 \\
Saponification number $(\mathrm{mg} \mathrm{KOH} / \mathrm{g})$ & 266.00 \\
Acid number $(\mathrm{mg} \mathrm{KOH} / \mathrm{g})$ & 2.0 \\
Iodine number $(\mathrm{mg} \mathrm{KOH} / \mathrm{g})$ & 12.90 \\
Flash point $\left({ }^{\circ} \mathrm{C}\right)$ & 280 \\
Cloud point $\left({ }^{\circ} \mathrm{C}\right)$ & 16 \\
Pour point $\left({ }^{\circ} \mathrm{C}\right)$ & 14 \\
\hline
\end{tabular}


value for catalytic esterification. The oil sample indicated saponification value of $266.00 \mathrm{mg}$ $\mathrm{KOH} / \mathrm{g}$ with a reasonably high value of flash point as $280^{\circ} \mathrm{C}$ making it safe for storage. The density of the oil was $0.9 \mathrm{~g} / \mathrm{cm}^{3}$ making it easy to handle.

Waste cooking oil was analysed for the presence of different carbon chain lengths, which can have potential for diesel formation as mentioned in section 2.1. The oil had different carbon chain lengths and degree of unsaturation (Table 2). This table indicates that the waste cooking oil consisted of various carbon chains (comp.) of fatty acids (F.A.) with the frequently detected ones were dodecanoic acid, tetra decanoic acid and hexadecenoic acid. These fatty acids are useful for biodiesel especially to be produced for engines.

\subsection{Characterization of catalyst for its selection for the better yield of biodiesel}

Catalysts SCC and DSCC were prepared and characterized as mentioned in section 2.2. For the selection of better catalyst for further preparation of biodiesel, important properties were determined (Table 3). The determinations indicated the higher percentage of carbon and fixed carbon (carbon in the solid form), higher acid density and BET surface area in DSCC compared to that of SCC. Also, there were lower percentages of ash contents and particle size in DSCC. All the properties favour the selection of DSCC over SCC.

SEM analysis of SCC and DSCC (Fig. 1) indicated the morphologically porous surface of DSCC compared to that of SCC, which is also confirmed by higher BET surface area of DSCC (Table 3). FT-IR analysis of SCC and DSCC indicates that DSCC has much more pronounced peaks of sulphonic $\left(-\mathrm{SO}_{3} \mathrm{H}\right)$, carboxylic $(-\mathrm{COOH})$ and hydroxyl $(-\mathrm{OH})$ groups, which would be helpful for increasing the FFA conversion. These pictures also indicate the abundant presence of lignocellulosic groups. Based on the comparison, DSCC was proved to be better catalyst for FFA conversion from waste cooking oil.

Table 2: Quantitative analysis of waste cooking oil.

\begin{tabular}{lllllllllll}
\hline Comp. & C6:0 & C8:0 & C10:0 & C12:0 & C14:0 & C15:0 & C16:0 & C18:0 & C18:1 & C18:2 \\
F.A. (\%) & 0.85 & 6.66 & 5.40 & 42.28 & 17.00 & 0.23 & 12.20 & 4.20 & 9.25 & 1.50 \\
\hline
\end{tabular}

Table 3: Properties of catalyst.

\begin{tabular}{lll}
\hline & $\begin{array}{l}\text { Catalyst prepared by } \\
\text { direct sulphonation of } \\
\text { coconut char (SCC) }\end{array}$ & $\begin{array}{l}\text { Catalyst prepared by diges- } \\
\text { tion of coconut char followed } \\
\text { by sulphonation (DSCC) }\end{array}$ \\
\hline Properties/Components & 2.9 & 1.0 \\
Ash content on a dry basis $(\%)$ & 16.9 \\
Volatile matter on a dry basis $(\%)$ & 25.1 & 82.1 \\
Fixed carbon on a dry basis $(\%)$ & 72.0 & $4.05(\mathrm{mmol} / \mathrm{g})$ \\
Total acid density & $3.2(\mathrm{mmol} / \mathrm{g})$ & 92.88 \\
Carbon $(\%)$ & 91.482 & 1.490 \\
Hydrogen $(\%)$ & 2.014 & 0.412 \\
Nitrogen $(\%)$ & 0.484 & 4.22 \\
Sulphur $(\%)$ & 3.12 & 413 \\
Surface Area $\left(\mathrm{m}^{2} . \mathrm{g}^{-1}\right)$ & 300 & 50.01 \\
Particle Size $(\mu \mathrm{m})$ & 55 & \\
\hline
\end{tabular}




\subsection{Optimization of parameters on biodiesel production with DSCC as a catalyst}

As discussed in section 2.4, diesel formation (FFA conversion) were studied for various parameters, $\mathrm{A}: \mathrm{O}$ ratio, catalyst loading, reaction temperature, keeping other parameters same with an aim to optimise the operating parameters (Figs. 3-5).

The optimised conditions proved to be A:O ratio of 18:01, catalyst loading of $5 \%$ and reaction time of 7 hours with the temperature at $65^{\circ} \mathrm{C}$, which was comparable to the literature [17]. At this optimised conditions, FFA conversion was $90.12 \%$ (biodiesel yield), which was calculated with the help of GC analysis, as shown in Fig. 6 along with FFA conversion formula mentioned in section 2.4. This value was slightly higher than that mentioned in the literature [25].

\subsection{Characterization of biodiesel produced at optimised conditions}

The biodiesel formed was subjected to various characterisations, as mentioned in section 2.5. Table 4 indicates all essential properties of biodiesel formed, which are comparable to standard values [26-27].

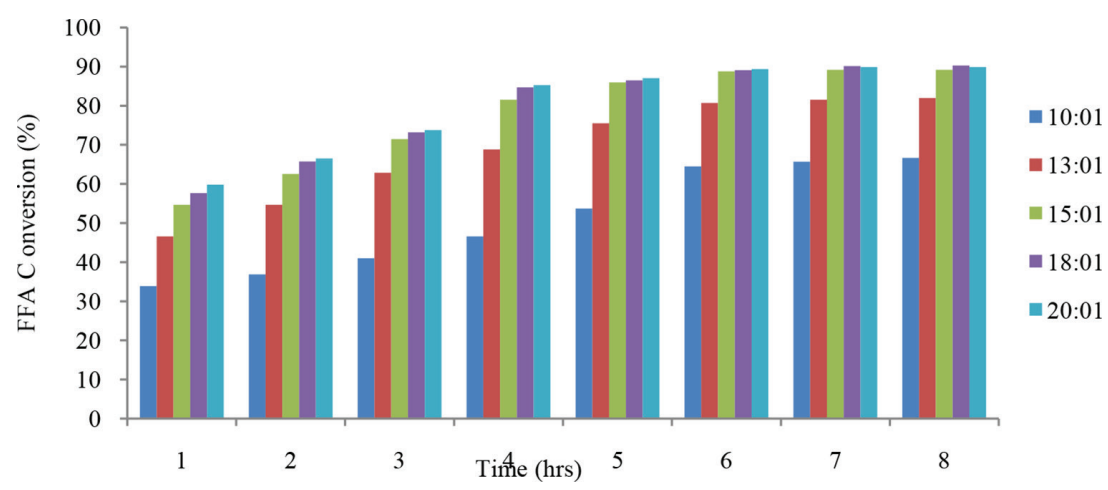

Figure 3: Effect of A:O ratio on FFA conversion with time, at $65^{\circ} \mathrm{C}$ with the catalyst loading of $5 \%$.

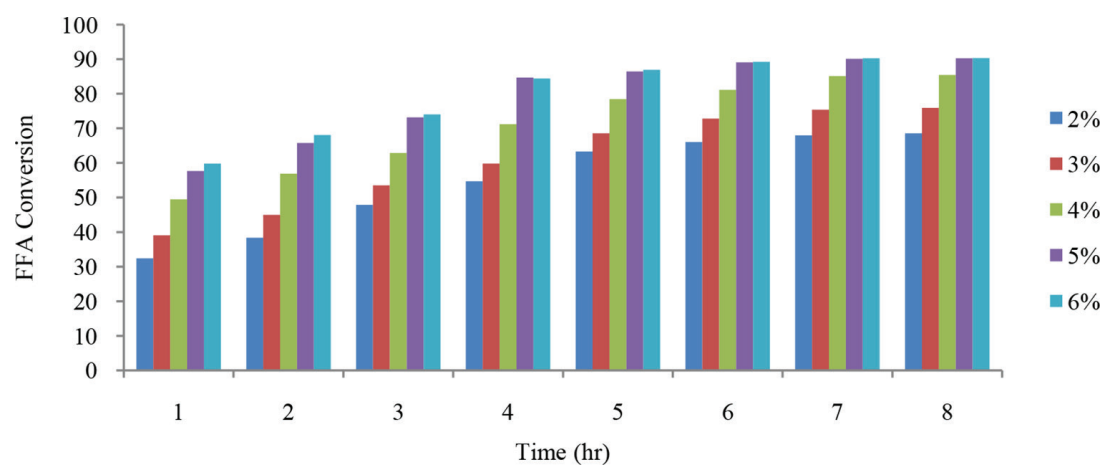

Figure 4: Effect of catalyst loading on FFA conversion with time, at $65^{\circ} \mathrm{C}$ with A:O ratio of 18:01. 


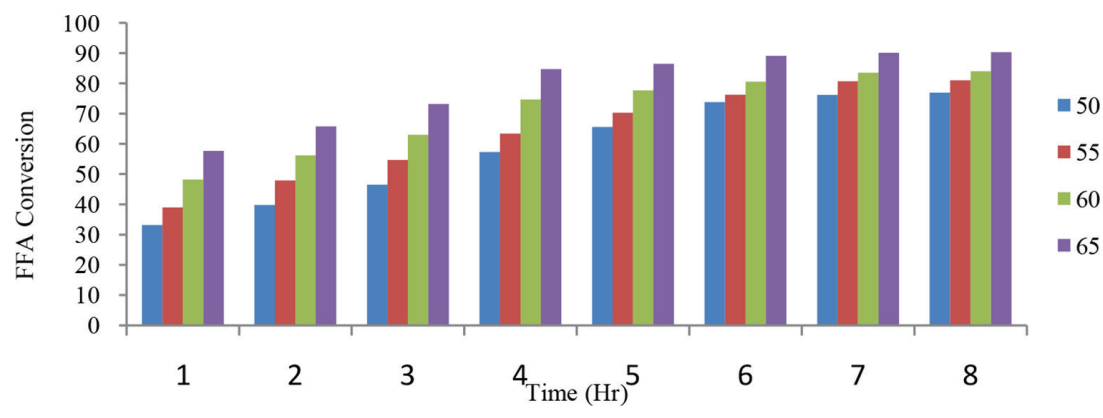

Figure 5: Effect of temperature on FFA conversion with time, for catalyst loading of 5\% and A:O ratio of 18:01.

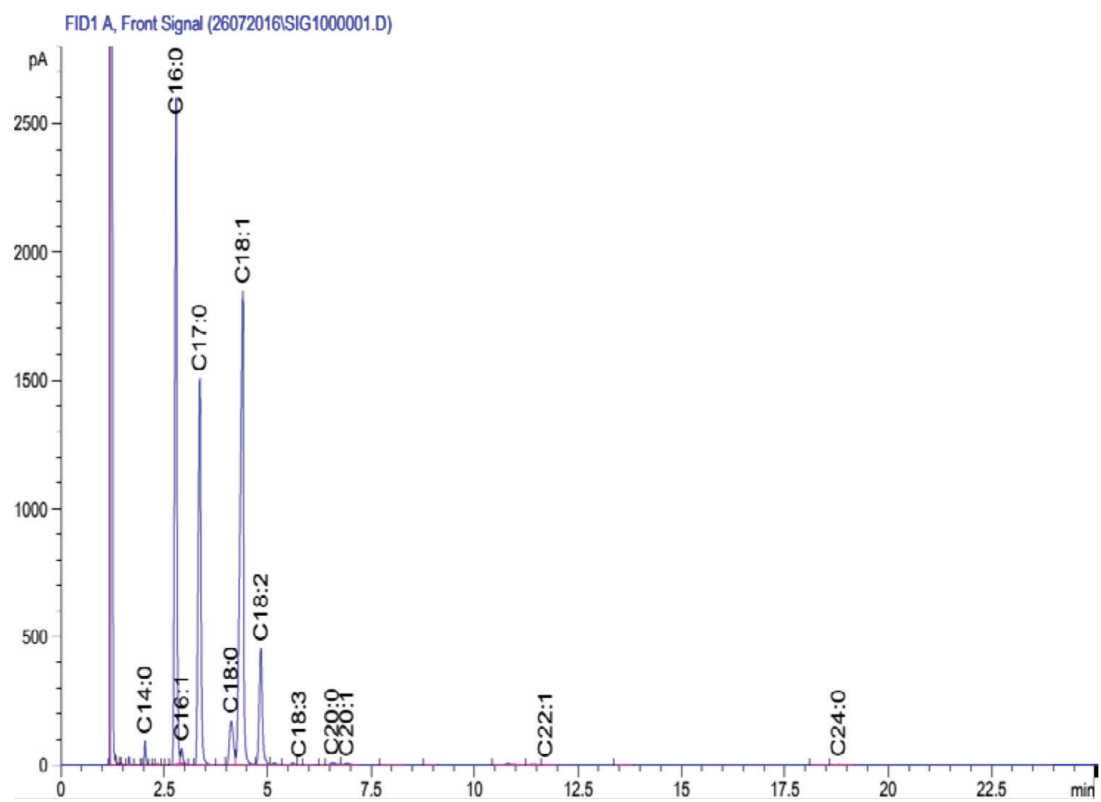

Figure 6: Gas - Chromatogram of FAME produced from waste cooking oil using DSCC.

Table 4: Properties of biodiesel.

\begin{tabular}{llll}
\hline Properties & Present study & IS $15607-2005$ & EN 14214 \\
\hline Calorific value $(\mathrm{MJ} / \mathrm{kg})$ & 47.5 & 45.54 & - \\
Flash point $\left({ }^{\circ} \mathrm{C}\right)$ & 152 & $120(\mathrm{~min})$. & $>101$ \\
Density at $15^{\circ} \mathrm{C}\left(\mathrm{kg} / \mathrm{m}^{3}\right)$ & 868 & $860-900$ & $860-900$ \\
$(K$.$) Viscosity at 40^{\circ} \mathrm{C}\left(\mathrm{mm}^{2} / \mathrm{s}\right)$ & 4.8 & $2.5-6$ & $3.5-5$ \\
Acid value $(\mathrm{mg} \mathrm{KOH} / \mathrm{g})$ & 0.45 & 0.80 max & 0.5 \\
Cloud point $\left({ }^{\circ} \mathrm{C}\right)$ & 2 & - & - \\
Pour point $\left({ }^{\circ} \mathrm{C}\right)$ & 0 & - & - \\
Cetane number & 50 & $40-55$ & - \\
\hline
\end{tabular}




\section{CONCLUSIONS}

Waste cooking oil utilised was from local restaurants with its acid value of $2.0 \mathrm{mg} \mathrm{KOH} / \mathrm{g}$, indicating its suitability for catalytic esterification. The oil as feedstock indicated saponification value of $266.00 \mathrm{mg} \mathrm{KOH} / \mathrm{g}$ with a reasonably high value of flash point as $280^{\circ} \mathrm{C}$ making it safe for storage. The GC analysis of oil as feedstock shows the presence of frequently detected peaks of fatty acids: dodecanoic, tetradecanoic and hexadecanoic, which is useful for biodiesel production especially to be used for engines.

Two types of catalysts were compared (prepared from coconut coir): SCC and DSCC. Based on characterisation DSCC indicated better catalyst with improved properties especially concerning fixed carbon, acid density and BET surface area. SEM analysis indicated the better morphological structure of DSCC. FT-IR analysis indicated significant presence of sulphonic $\left(-\mathrm{SO}_{3} \mathrm{H}\right)$, carboxylic $(-\mathrm{COOH})$ and hydroxyl $(-\mathrm{OH})$ groups.

Waste cooking oil as feedstock with DSCC as the catalyst yielded $90.12 \%$ of biodiesel at optimised conditions of various parameters, i.e. A:O, catalyst loading, reaction time and reaction temperature. Biodiesel obtained had properties of fuel compared to that of standard values.

\section{ACKNOWLEDGEMENTS}

Authors express their gratitude to SSS-NIRE, Kapurthala, Punjab and CIL, Panjab University, Chandigarh from India for various analyses required for this publication.

\section{REFERENCES}

[1] Castaldi, M., van Deventer, J., Lavoie, J.M., Legrand, J., Nzihou, A., Pontikes, Y., Py, X., Vandecasteele, C., Vasudevan, P.T. \& Verstraete, W., Progress and prospects in the field of biomass and waste to energy and added-value materials. Waste and Biomass Valorization, 8(6), pp. 1875-1884, 2017. https://doi.org/10.1007/s12649017-0049-0

[2] Balat, M. \& Balat, H., Progress in biodiesel proceedings. Applied Energy, 87, pp. 18151835, 2010. https://doi.org/10.1016/j.apenergy.2010.01.012

[3] Dorado, M.P., Ballesteros, E., Arnal, J.M. \& Lopez, F.Z., Exhaust emissions from a diesel engine fuelled with transesterified waste olive oil. Fuel, 82(11), pp. 1311-1315, 2003. https://doi.org/10.1016/s0016-2361(03)00034-6

[4] Lin, C.Y., Lin, H.A. \& Hung, L.B., Fuel structure and properties of biodiesel produced by the peroxidation process. Fuel, 859(12-13), pp. 1743-1749, 2006. https://doi. org/10.1016/j.fuel.2006.03.010

[5] Bankovic-llic, I.B., Stamenkovic, O.B. \& Veljkovic, V.B., Biodiesel production from non-edible plant oils. Renewable and Sustainable Energy Reviews, 16(6), pp. 36213647, 2012. https://doi.org/10.1016/j.rser.2012.03.002

[6] Bankovic-llic, I.B., Stojkovic, I.J., Stamenkovic, O.S., Veljkovic, V.B. \& Hung, Y.T., Waste animal fats as feedstocks for biodiesel production. Renewable and Sustainable Energy Reviews, 32, pp. 238-254, 2014. https://doi.org/10.1016/j.rser.2014.01.038

[7] Atadashi, I.M., Aroua, M.K., Aziz, A.R.A. \& Sulaiman, N.M.N., The effects of catalysts in biodiesel production: a review. Journal of Industrial and Engineering Chemistry, 19(1), pp. 14-26, 2013. https://doi.org/10.1016/j.jiec.2012.07.009

[8] Reddy, C.R.V., Oshel, R. \& Verkade, J.G., Room-temperature conversion of soyabean oil and poultry fat to biodiesel catalysed by nanocrystalline calcium oxides. Energy Fuels, 20(6), pp. 1310-1314, 2006. https://doi.org/10.1021/ef050435d 
[9] Toda, M., Takagaki, A., Okamura, M., Kondo, J.N., Hayashi, S., Domen, K. \& Hara, M., Green chemistry: biodiesel made with sugar catalyst. Nature, 438(7065), pp. 178178, 2005. https://doi.org/10.1038/438178a

[10] Budarin, V., Clark, J.H., Hardy, J.J., Luque, R., Milkowski, K., Tavener, S.J. \& Wilson, A.J., Starbons: new starch-derived mesoporous carbonaceous materials with tunable properties. Angewandte Chemie, 118(23), pp. 3866-3870, 2006. https://doi. org/10.1002/ange.200600460

[11] Budarin, V.L., Clark, J.H., Luque, R., Macquarrie, D.J., Koutinas, A. \& Webb, C., Tunable mesoporous materials optimized for aqueous phase esterification. Green Chemistry, 9(9), pp. 992-995, 2007. https://doi.org/10.1039/b704055e

[12] Kitano, M., Arai, K., Kodama, A., Kousaka, T., Nakajima, K., Hayashi, S. \& Hara, M., Preparation of a sulfonated porous carbon catalyst with the high specific surface area. Catalysis Letters, 131(1-2), pp. 242-249, 2009. https://doi.org/10.1007/s10562-0090062-4

[13] Shu, Q., Zhang, Q., Xu, G., Nawaz, Z., Wang, D. \& Wang, J., Synthesis of biodiesel from cottonseed oil and methanol using a carbon-based solid acid catalyst. Fuel Processing Technology, 90(7), pp. 1002-1008, 2009. https://doi.org/10.1016/j.fuproc.2009.03.007

[14] Mo, X., Lotero, E., Lu, C., Liu, Y. \& Goodwin, J.G., A novel sulfonated carbon composite solid acid catalyst for biodiesel synthesis. Catalysis Letters, 123 (1-2), pp. 1-6, 2008. https://doi.org/10.1007/s10562-008-9456-y

[15] Liu,Y., Chen, J., Yao, J.,Lu, Y.,Zhang,L.\& Liu, X., Preparation and properties of sulfonated carbon-silica composites from sucrose dispersed on MCM-48. Chemical Engineering Journal, 148(1), pp. 201-206, 2009. https://doi.org/10.1016/j.cej.2009.01.010

[16] Villa, A., Tessonnier, J.P., Majoulet, O., Su, D.S. \& Schlögl, R., Amino-functionalized carbon nanotubes as solid basic catalysts for the transesterification of triglycerides. Chemical Communications, 29, pp. 4405-4407, 2009. https://doi.org/10.1039/ b906123a

[17] Sontakke, A.D. \& Jha, P., Study of esterification of waste cooking oil using solid acid catalyst derived from coconut coir. International Journal of Engineering and Management Research, 7(3), pp. 363-366, 2017.

[18] Atabani A.E., Non-edible vegetable oils: a critical evaluation of oil extraction, fatty acid compositions, biodiesel production, characteristics, engine performance and emissions production. Renewable and Sustainable Energy Reviews, 18, pp. 211-245, 2013. https://doi.org/10.1016/j.rser.2012.10.013

[19] Iyer, P.V.R., Rao, T.R. \& Grover, P.D., Biomass Thermo-Chemical Characterization, Chemical Engineering Department, IIT Delhi, p. 45, 2002.

[20] Srihari, V. \& Das, A., Applied Ecology and Environmental Research, 1, p. 13, 2009.

[21] ASTM International, D4607-94, 2011.

[22] Siggia, S, Quantitative Organic Analysis via Functional Groups, 3rd edn., John Wiley \& Sons: New Jersey, p. 54, 1967.

[23] Chouhan, A.S. \& Sarma, A.K., Modern heterogeneous catalysts for biodiesel production: a comprehensive review. Renewable and Sustainable Energy Reviews, 15(9), pp. 4378-4399, 2011. https://doi.org/10.1016/j.rser.2011.07.112

[24] Chitra, P., Venkatachalam, P. \& Sampathrajan, A., Optimisation of experimental conditions for biodiesel production from alkali-catalysed transesterification of Jatropha curcus oil. Energy for Sustainable Development, 9, pp. 13-18, 2005. https://doi. org/10.1016/s0973-0826(08)60518-9 
[25] Bankovic-Ilic, I.B., Stamenkovic, O.S. \& Veljkovic, V.B., Biodiesel production from non-edible plant oils. Renewable and Sustainable Energy Reviews, 16, pp. 3621-3647, 2012. https://doi.org/10.1016/j.rser.2012.03.002

[26] Verma, P. \& Sharma, M.P., Comparative analysis of the effect of methanol and ethanol on Karanja biodiesel production and its optimisation. Fuel, 180, pp. 164-174, 2016. https://doi.org/10.1016/j.fuel.2016.04.035

[27] Phan, A.N. \& Phan, T.M., Biodiesel production from waste cooking oil. Fuel, 87, pp. 3490-3496, 2008. https://doi.org/10.1016/j.fuel.2008.07.008 